\title{
Rehabilitation of postural stability in ataxic/hemiplegic patients after stroke
}

\author{
Filipa Januário $^{1}$, Inês Campos ${ }^{1}$, Carla Amaral ${ }^{1}$ \\ ${ }^{1}$ Department of Physical Medicine and Rehabilitation, Coimbra University Hospital, \\ Portugal
}

Filipa Januário

Serviço de Medicina Física e de Reabilitação

Hospitais da Universidade de Coimbra

Address: Av. Bissaya Barreto e Praceta Prof. Mota Pinto

3000-075 Coimbra

Portugal

Telephone: +351239400555

Fax: + 351239400495

fajanuario@gmail.com 


\section{Abstract}

Purpose: This study assesses the postural stability and the effect of balance training using a force platform visual biofeedback among outpatients with postural disturbances following stroke. Method: A tilting multiaxial force platform was used to assess bilateral postural stability in 38 outpatients (mean age $69.50 \pm 8.57$ years) with hemiplegia and/or ataxia after stroke. Stability indexes were obtained. Afterwards, a subgroup of 12 patients with the poorest overall stability index (OASI) started a balance training programme in the force platform. Postural control training consisted of a 30 minute training session once a week for a 15 week period. The test was then repeated. Results: In the 38 outpatients sample the mean OASI was $4.7 \pm 2.0$ and $42.1 \%$ of the patients used their hands for support. In the 12 outpatients group, the initial OASI was $5.8 \pm 2.3$ and half of the patients used their hands for support. The final OASI was $3.3 \pm 1.0(\mathrm{p}=0.005)$ and only 2 of the patients used their hands for support $(\mathrm{p}=0.046)$. Conclusion: Our results suggest that a training program using force platform visual biofeedback improves objective measures of bilateral postural stability in patients with hemiplegia and/or ataxia after stroke.

Key-Words: Postural balance, cerebrovascular stroke, rehabilitation, functional capacity evaluation

\section{Introduction:}

Balance is essential to all functional activities during sitting and standing [1]. Postural control is fundamental to maintain balance. The important resources for postural control are movement strategies, biomechanical constraints, cognitive processing, perception of the verticality (visual and postural), sensory modalities (somatosensory, visual and vestibular) and the sensory reintegration and reweighting in central nervous system (CNS) [2], which can be impaired after a stroke. 
Cerebrovascular disease is an important health problem [3]. The incidence of stroke in Portugal in 1998 was $181.7 \%$ [4]. After stroke, some patients are unable to stand, and others have higher postural sway, asymmetric weight distribution, impaired weightshifting ability and equilibrium reactions may be delayed or disrupted [5-8]. There is also an increased risk of falling, resulting in high economic costs and social problems [9-11]. Hemiplegia can cause reduction in patients limits of stability, which are defined as the area where the individual can shift his centre of mass without loss of balance and without changing the support base. This describes a theoretical cone extending around a person's feet [12].

Impaired balance greatly influences the activities of daily living (ADL), independence and gait. Therefore, it's essential to rapidly achieve postural control in order to improve independence, social participation and general health [13].

The aim of balance rehabilitation is to ensure safe ambulation [14]. In spite of the multiple therapeutic approaches to promote recovery of postural control, no definitive conclusions can be drawn on which one is the best. Force platform systems (posturography) are designed to provide visual or auditory feedback to patients regarding the focus of their centre-of-pressure (COP). In these systems, feedback is defined as augmented extrinsic information about task success provided to the performer. It's thought that, by giving patients additional information, they will become more aware of the body's displacements and orientation in space. It is believed that the relearning of postural control through external biofeedback is an effective therapy for improving balance control [15].

Hocherman et al. concluded that the hemiplegic patients stability of stance on a moving platform could be improved by regular training [16]. Shumway-Cook et al. showed that postural sway biofeedback was more effective than conventional therapy in 
retraining postural stability in hemiplegic patients [17]. Cheng et al. achieved a significant improvement in sit-to-stand performance in hemiplegic stroke patients in the training group with standing biofeedback trainer. Body weight was distributed more symmetrically in both legs, with less mediolateral sway when rising and sitting down [18]. Although there is considerable number of studies, there is no evidence of which is the more effective approach to facilitate the natural recovery of standing balance following stroke. In a Cochrane's review of seven randomized controlled trials, Barclay-Goddard et al. concluded that force plate feedback improved stance symmetry after stroke, without repercussion on postural sway or measures related to gait and independency in ADL [19]. In the review of Van Peppen et al., based on randomized controlled trials and controlled clinical trials, they concluded that visual feedback therapy should not be favoured over conventional therapy [20]. Geiger et al. concluded that combining force platform visual feedback training with conventional physical therapy did not enhance the effects of conventional physical therapy on balance and functional mobility skills in stroke patients with hemiplegia [21].

The present study is designed to assess postural stability and the effect of balance training using force platform visual biofeedback among patients with postural disturbances following stroke.

\section{Material and Methods:}

The trial included a sample of 38 outpatients with hemiplegia and/or ataxia after stroke. Stroke was defined as an acute event of cerebrovascular origin causing focal or global neurological dysfunction lasting more than $24 \mathrm{hrs}$, and diagnosed by a Neurologist and confirmed by computed tomography or magnetic resonance imaging. Patients with impaired balance were recruited to this study, referred by the Physiatrists 
from our department.

Patients were required to meet the following criteria for inclusion in the study: (1) ability to understand and follow simple verbal instructions, (2) ambulatory after stroke, (3) ability to stand with or without assistance (with Medical Research Council Scale for Muscle Strength grade $\geq 4$ at the lower limb), (4) no medical contraindication to exercising. They were excluded if they had a history of any other neurological pathology, severe spasticity, other conditions affecting balance, hemineglect, dementia, cognitive deficit, impaired vision or concomitant medical illness or musculoskeletal conditions affecting lower limbs.

The Biodex Stability System (BSS)® (Biodex Medical Systems, Shirley, NY, USA) was used for both balance function assessment and training. BSS is a tilting multiaxial platform, with a maximum inclination of 20 degrees, 8 resistance levels and permits visual biofeedback with the centre of pressure presented on the monitor [22]. The overall stability index (OASI), mediolateral stability index (MLSI) and anteroposterior stability index (APSI) were obtained for the 38 patients by doing a test at level 8 for 20 seconds, with eyes open. The patients were asked for keeping the centre of pressure in the centre of a target displayed on the monitor. Only if necessary, patients could support themselves with their hands, and this was noted. Before the test, the patients did one training test. It was performed as a single test to reduce the potential effects of learning and fatigue.

We selected a subgroup of 12 outpatients with the poorest OASI, to assess the effects of balance training on postural stability. The balance training protocol consisted of bilateral stance weight-shifting exercises (mediolateral, right and left diagonal) where patients were asked to draw a straight line on the monitor. At the end they must stand still in an orthostatic position. Each session lasted 30 minutes, performed once a week, 
for 15 weeks. All patients started at level 8 and the resistance level was progressively decreased, in order to increase difficulty. Patients could hold on the support rails if necessary. During the training sessions, patients used visual feedback. After training completion, the test was repeated for these 12 patients in the same conditions as the initial test.

Data analysis was performed using SPSS for Macintosh version 16.0 (SPSS Inc, Chicago, IL, USA). Wilcoxon Test was used to compare the initial and final OASI and the hands support in the balance training subgroup of 12 patients. Significance was set at 0.05 .

At last, to homogenize the sample age, we selected the 10 patients from 12 patients subgroup, whose age group could be compared the BSS group 3 (table 1). It was compared the final OASI with the reference values of Biodex Stability System database.

\section{Results:}

The sample consisted in 38 (20 men, 18 women) outpatients with a mean age of $69.50 \pm 8.57(\mathrm{SD})$ years and a mean time since stroke of $22.66 \pm 40.48$ months. These hemiplegic and/or ataxic patients had cerebral, cerebellar, or brainstem ischemic/hemorrhagic stroke (see Table 2 and 3).

In this sample, the mean OASI was $4.7 \pm 2.0$, the mean APSI was $3.4 \pm 1.6$ and the mean MLSI was $3.3 \pm 1.6$. The OASI value of these patients exceeds the reference OASI interval, regarding the mean age (69.5 years/group 3) (see Table 1) [23]. During this assessment $42.1 \%(n=16)$ of the patients used their hands for support.

The subgroup of the 12 patients ( 7 men, 5 women) had a mean age of $65.17 \pm 7.10$ years and a mean time since stroke of $22.17 \pm 26.38$ months. Ten patients can be included in group 3, one patient in group 2 and the other in group 4 (see Table 1). These 
patients also had various types of stroke and different impairments as shown in Table 2 and 3. In this group, the mean initial OASI was $5.82 \pm 2.38$ and the mean final OASI was $3.30 \pm 1.09$. According to the Wilcoxon Test there was a statistically significant improvement of OASI $(\mathrm{p}=0.005)$. The mean improvement was 2.51 . Before the balance training, 6 patients (50\%) supported their hands. In the final test only 2 patients supported their hands, producing a statistically significant improvement $(\mathrm{p}=0.046)$.

For the 10 patients group, the mean initial OASI was $5.35 \pm 1.88$ and the mean final OASI was $3.24 \pm 1.19$. Comparing to the BSS references values, the latter is included in the OASI normal interval range. According to the Wilcoxon Test there was also a statistically significant improvement of OASI $(\mathrm{p}=0.012)$.

\section{Discussion:}

Following stroke, postural deficits are common [24]. In the hemiparetic gait there is reduced weight-bearing on the paretic limb [25-27] and excessive postural sway $[28,29]$. Improvement in gait symmetry is very important to the balance recovery [30].

The results of this study show that there is a statistically significant improvement in OASI with approximation to the reference values (predictive values, BSS database) at the same age range. There is also a significant reduction on hand's support. These results are in agreement with the patients verbal reports that training on the platform made them feel more stable and secure, with an increase of self-confidence for standing and gait.

Postural control is considered to be a prerequisite for restoration of independent living. In spite of patients' subjective improvement, objective measures of ADL performance weren't assessed. Sacley et al. studied the effect of the visual feedback after stroke in a randomized controlled trial. They assessed sway and stance symmetry, 
motor and ADL function at 0,4 and 12 weeks. They concluded that significant improvements were seen in the treatment group in measures of sway, stance symmetry, motor and ADL function, but differences between groups had disappeared at 3 months [31]. There is no follow up in our study, so conclusions about gain maintenance can't be drawn. Chen et al. studied the effect of balance training on hemiplegic stroke patients, using 2 groups that received a conventional programme. Only the treatment group received visual feedback balance training. They concluded that there were significant improvements of dynamic balance function and ADL function at 6 months of follow-up in the treatment group [32]. Yavuzer et al. studied the effects of balance training on quantitative gait characteristics in a randomized controlled trial. They concluded that balance training using platform biofeedback in addition to a conventional rehabilitation programme is beneficial in improving postural control and weight-bearing on the paretic side, 6 months after stroke [33].

Like the forementioned studies we also found a balance improvement. However this study doesn't have a control group, so the results were compared with the reference values of BSS. Others limitations of this study are the reduced number of patients and the use of the same instrument for assessment and training. This study has a heterogeneous sample due to various types of stroke, different impairments and different times since stroke, with most patients in a chronic phase (mean 22.17 months after stroke). More studies with homogeneous groups of patients are needed.

In conclusion, the results suggest that a training programme using force platform visual biofeedback improves objective measures of bilateral postural stability in patients with hemiplegia and/or ataxia after stroke, even in a chronic phase when significant motor recovery or neurological gains are not expected.

It may be important to associate biofeedback balance training to conventional 
programmes.

In the future, more patients will be included, divided by stroke pattern, applied an ADL scale and provided a post treatment follow-up analysis.

\section{References:}

1 - Eser F, Yavuzer G, Karakus D, Karaoglan B. The effect of balance training on motor recovery and ambulation after stroke: a randomized controlled trial. Eur J Phys Rehabil Med 2008;44:19-25.

2 - Oliveira CB, Medeiros IT, Frota NF, Greters ME, Conforto AB. Balance control in hemiparetic stroke patients: Main tools for evaluation. J Rehabilit Res Dev 2008;45(8):1215-26.

3 - Glanz M, Klawansky S, Chalmers T. Biofeedback therapy in stroke rehabilitation: a review. J R Soc Med 1 997;90(1):33-9.

4 - Nunes JM. Rede de Referenciação Hospitalar de Medicina Física e de Reabilitação. Direcção-Geral da Saúde. 2003. 68 p.

5 - Goldie PA, Matyas TA, Evans OM, Galea M, Bach TM. Maximum voluntary weight-bearing by the affected and unaffected legs in standing following stroke. Clin Biomech. 1996; 11(6):333-42.

6 - Badke MB, Duncan PW. Patterns of Rapid Motor Responses During Postural Adjustments When Standing in Healthy Subjects and Hemiplegic Patients. Phys Ther $1983 ; 47: 1020-8$.

7 - Horak FB, Esselman P, Anderson ME, Lynch MK. The effects of movement velocity, mass displaced, and task certainty on associated postural adjustments made by normal and hemiplegic individuals. J Neurol Neurosurg Psychiatry 1984;47:1020-8.

8 - Dickstein R, Abuluflo N. Postural Sway of the Affected and Nonaffected Pelvis and 
Leg in Stance of Hemiparetic Patients. Arch Phys Med Rehabil 2000;81(3):364-7.

9 - Lamb SE, Ferrucci L, Volapto S, Fried LP, Guralnik JM. Women's Health and Aging Study. Risk factors for falling in home dwelling older women with stroke: The Women's Health and Aging Study. Stroke 2003;34(2):494-501.

10 - Harris JE, Eng JJ, Marigold DS, Tokuno CD, Louis CL. Relationship of balance and mobility to fall incidence in people with chronic stroke. Phys Ther. $2005 ; 85(2): 150-8$.

11 - Belgen B, Beninato M, Sullivan PE, Narielwalla K. The association of balance capacity and falls self-efficacy with history of falling in community-dwelling people with chronic stroke. Arch Phys Med Rehabil 2006;87(4):554-61.

12 - McCollum G, Leen TK. Form and exploration of mechanical stability limits in erect stance. J Motor Behav 1989;21:225-44.

13 - Geurts AC, de Haart M, van Nes IJ, Duysens J. A review of standing balance recovery from stroke. Gait Posture 2005;22:267-81.

14 - Bonan IV, Yelnik AP, Colle FM, Michaud C, Normand E, Panigot B, Roth P, Guichard JP, Vicaut E. Reliance on visual information after stroke. Part II: Effectiveness of a balance rehabilitation program with visual cue deprivation after stroke: a randomized controlled trial. Arch Phys Med Rehabil 2004;85:274-8.

15 - Walker C, Brouwer BJ, Culham EG. Use of Visual Feedback in Retraining Balance Following Acute Stroke. Phys Ther 2000;80:886-95.

16 - Hocherman S, Dickstein R. Platform training and postural stability in hemiplegia. Arch Phys Med Rehabil 1984;65:588-92.

17 - Shumway-Cook A, Anson D, Haller S. Postural sway biofeedback: its effect on reestablishing stance stability in hemiplegic patients. Arc Phys Med Reahabil 1988;69:395-400. 
18 - Cheng PT, Wu SH, Liaw MY, Wong AM, Tang FT. Symmetrical body-weight distribution training in stroke patients and its effect on fall prevention. Arch Phys Med Rehabil 2001;82(12):1650-4.

19 - Barclay-Goddard R, Stevenson T, Poluha W, Moffatt ME; Taback, SP. Force platform feedback for standing balance training after stroke. Cochrane Database Syst Rev 2004;18(4):CD004129.

20 - Van Peppen R, Kortsmit M, Lindeman E, Kwakkel G. Effects of visual feedback therapy on postural control in bilateral standing after stroke: a systematic review. J Rehabil Med 2006;38(1):3-9.

21 - Geiger RA, Allen JB, O'keefe J, Hicks RR. Balance and mobility following stroke: effects of physical therapy interventions with and without biofeedback/forceplate training. Phys Ther 2004;81:995-1005.

22 - Arnold BL, Scmitz RJ. Examination of balance measures produced by the Biodex Stability System. J Athl Train 1998;33(4):323-27.

23 - Finn JA, Alvarez MM, Jett RE, Axtell RS, Kemler DS. Stability performance assessment among subjects of disparate balancing abilities. Med Sci Sports Exerc 1999;31(5):S252.

24 - Dault M, de Haart M, Geurts AC, Arts IM, Nienhuis, B. Effects of visual center of pressure feedback on postural control in young and elderly healthy adults and in stroke patients. Hum Mov Sci 2003;22(3):221-36.

25 - Yavuzer G, Ergin S. Effect of an arm sling on gait pattern in patients with hemiplegia. Arch Phys Med Rehabil 2002;83:960-3.

26 - Wong A, Lee MY, Kuo JK, Tang, FT. The Development and Clinical Evaluation of a Standing Biofeedback Trainer. J Rehabil Res Dev 1997;34( 3):322-327.

27 - Sacley C. The relationships between weight-bearing asymmetry after stroke, motor 
function and activities of daily living. Physiotherapy Theory Pract 1990;6:179-85.

28 - de Haart M, Geurts AC, Huidekoper SC, Fasotti L, van Limbeek J. Recovery of standing balance in postacute stroke patients: a rehabilitation cohort study. Arch Phys Med Rehabil 2004;85:886-95.

29 - Bonan IV, Colle FM, Guichard JP, Vicaut E, Eisenfisz M, Tran Ba Huy P, Yelnik AP. Reliance on visual information after stroke. Part I: Balance on dynamic posturography. Arch Phys Med Rehabil 2004;85:268-73.

30 - Hsu A-L, Tang P-F, Jan M-H. Analysis of impairments influencing gait velocity and asymmetry of hemiplegic patients after mild to moderate stroke. Arch Phys Med Rehabil 2003;84:1185-93.

31 - Sacley CM, Lincoln NB. Single blind randomized controlled trial of visual feedback after stroke: effects on stance symmetry and function. Disabil Rehabil 1997;19(12):536-46.

32 - Chen IC, Cheng PT, Chen CL, Chen SC, Chung CY, Yeh TH. Effects of Balance Training on Hemiplegic Stroke Patients. Chang Chung Med J 2002;25(9):583-90.

33 - Yavuzer G, Eser F, Karakus D, Karaoglan B, Stam HJ. The effects of balance training on gait late after stroke: a randomized controlled trial Clin Rehabil. 2006;20(11):960-9. 
Table 1 - Reference Values of Biodex Stability System

\begin{tabular}{|c|c|c|c|}
\hline Reference Values & Age (years) & OASI interval & OASI mean \\
\hline Group 1 & $17-35$ & $0.82-2.26$ & 1.54 \\
\hline Group 2 & $36-53$ & $1.23-3.03$ & 2.13 \\
\hline Group 3 & $54-71$ & $1.79-3.35$ & 2.57 \\
\hline Group 4 & $72-89$ & $1.9-3.5$ & 2.7 \\
\hline
\end{tabular}

Legend: Adapted from Finn JA, Alvarez MM, Jett RE, Axtell RS, Kemler DS. Stability performance assessment among subjects of disparate balancing abilities. Med Sci Sports Exerc 1999;31(5):S252

Table 2 - Stroke types

\begin{tabular}{|c|c|c|c|c|}
\hline \multirow[t]{2}{*}{ Stroke type } & \multicolumn{2}{|c|}{ Sample of 38 outpatients } & \multicolumn{2}{|c|}{$\begin{array}{c}\text { Balance training group } \\
\text { of } 12 \text { outpatients }\end{array}$} \\
\hline & Frequency & Percent & Frequency & Percent \\
\hline Ischemic cerebral & 19 & 50.0 & 5 & 41.7 \\
\hline Hemorragic cerebral & 2 & 5.3 & 0 & 0 \\
\hline Ischemic cerebellar & 5 & 13.2 & 1 & 8.3 \\
\hline $\begin{array}{l}\text { Hemorragic } \\
\text { cerebellar }\end{array}$ & 3 & 7.9 & 3 & 25.0 \\
\hline Ischemic brainstem & 5 & 13.2 & 1 & 8.3 \\
\hline $\begin{array}{l}\text { Hemorragic } \\
\text { brainstem }\end{array}$ & 3 & 7.9 & 1 & 8.3 \\
\hline Multiple strokes & 1 & 2.6 & 1 & 8.3 \\
\hline Total & 38 & 100 & 12 & 100 \\
\hline
\end{tabular}


Table 3 - Types of Imparment

\begin{tabular}{|c|c|c|c|c|}
\hline \multirow[t]{2}{*}{ Impairment } & \multicolumn{2}{|c|}{ Sample of 38 outpatients } & \multicolumn{2}{|c|}{$\begin{array}{c}\text { Balance training group of } 12 \\
\text { outpatients }\end{array}$} \\
\hline & Frequency & Percent & Frequency & Percent \\
\hline Ataxic gait & 9 & 23.7 & 2 & 16.7 \\
\hline Right hemiplegia & 7 & 18.4 & 3 & 25.0 \\
\hline Left hemiplegia & 7 & 18.4 & 0 & 0 \\
\hline $\begin{array}{l}\text { Ataxic gait }+ \text { right } \\
\text { hemiplegia }\end{array}$ & 6 & 15.8 & 3 & 25.0 \\
\hline $\begin{array}{l}\text { Ataxic gait + left } \\
\text { hemiplegia }\end{array}$ & 8 & 21.1 & 4 & 33.3 \\
\hline Others & 1 & 2.6 & 0 & 0 \\
\hline Total & 38 & 100 & 12 & 100 \\
\hline
\end{tabular}

